\title{
KEY FACTS ON FAMILY FOUNDATIONS
}

\section{Grantmaker Data, 2009}

The Foundation Center has identified 38,701 grantmaking independent foundations with measureable donor or donor-family involvement. These "family foundations" represent more than half of all independent foundations and account for similar shares of independent foundations' giving, assets, and new gifts and bequests from donors. If all of the nation's family foundations could be identified, these shares would undoubtedly rise. ${ }^{1}$

Between 2008 and 2009, giving by grantmaking family foundations decreased 4 percent. The reduction stood in contrast to the 14.4 percent increase in the prior year.

${ }^{1}$ Family foundations are not legally distinct from other independent foundations, requiring the Foundation Center to identify them using several objective and subjective criteria. These criteria include independent foundations with "family" or "families" in their name, a living donor whose surname matches the foundation name, or at least two trustee surnames that match a living or deceased donor's name, along with any independent foundations that self-identify as family foundations on annual Foundation Center surveys.

Summary Statistics for Grantmaking Family Foundations, 2008 and 2009

\begin{tabular}{lrrc}
\hline & \multicolumn{1}{c}{$\mathbf{2 0 0 8}$} & \multicolumn{1}{c}{$\mathbf{2 0 0 9 ^ { 1 }}$} & \% Change $^{2}$ \\
\hline No. of Foundations & 38,339 & 38,701 & 0.9 \\
Total Giving & $\$ 21,117,277$ & $\$ 20,268,001$ & $-4.0^{3}$ \\
Total Assets & $\$ 246,044,927$ & $\$ 247,669,220$ & 0.7 \\
Gifts Received & $\$ 19,068,875$ & $\$ 17,261,950$ & -9.5 \\
\hline
\end{tabular}

Note: Dollars in thousands. Excludes 2,992 family foundations that did not report giving in the latest fiscal year. These foundations held $\$ 2.2$ billion in assets in 2009 and reported gifts received totalling $\$ 1$ billion.

${ }^{1}$ Figures for 2009 are preliminary.

2Percent change represents current dollars.

${ }^{3}$ Excluding the Bill \& Melinda Gates Foundation, giving decreased 6 percent.

Inflation-adjusted Family Foundation Giving, 1999 to 2009

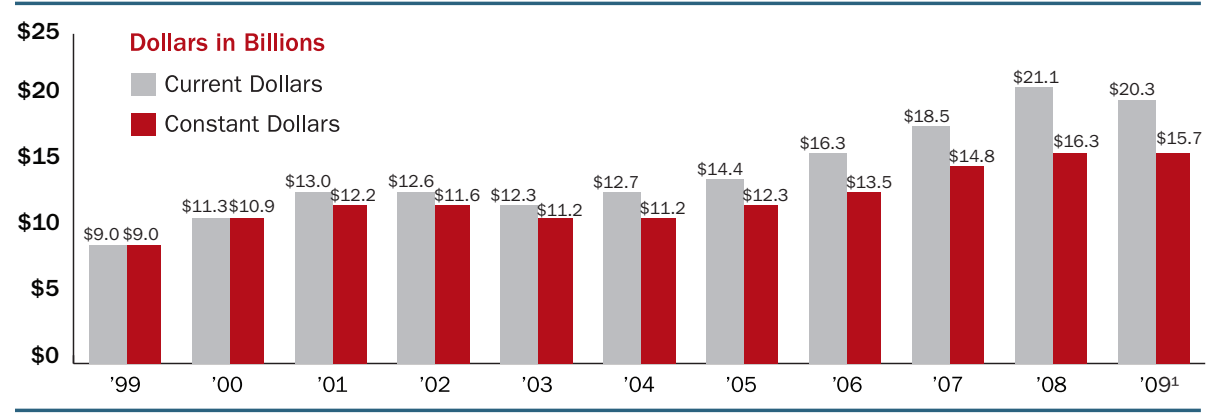

${ }^{1}$ Figures for 2009 are preliminary.

\section{\$20.3 billion}

Giving by family

foundations in 2009

$$
-4 \%
$$

Decrease in family foundation giving between

2008 and 2009

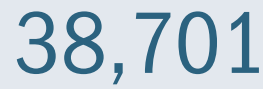

Number of grantmaking family foundations

in 2009

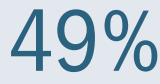

Share of family foundations reporting less than $\$ 50,000$ in

giving in 2009

$$
62 \%
$$

Family foundation giving as a share of all independent foundation giving in 2009 


\section{Giving Patterns, 2009}

Larger family foundations included in the Foundation Center's 2009 grants sample ${ }^{1}$ were more likely to provide funding for health, education, international affairs, science and technology, and religion than independent foundations overall. They were less likely to give for human services, public affairs/society benefit, arts and culture, and the social

\section{Larger family foundations favored health and education in 2009}

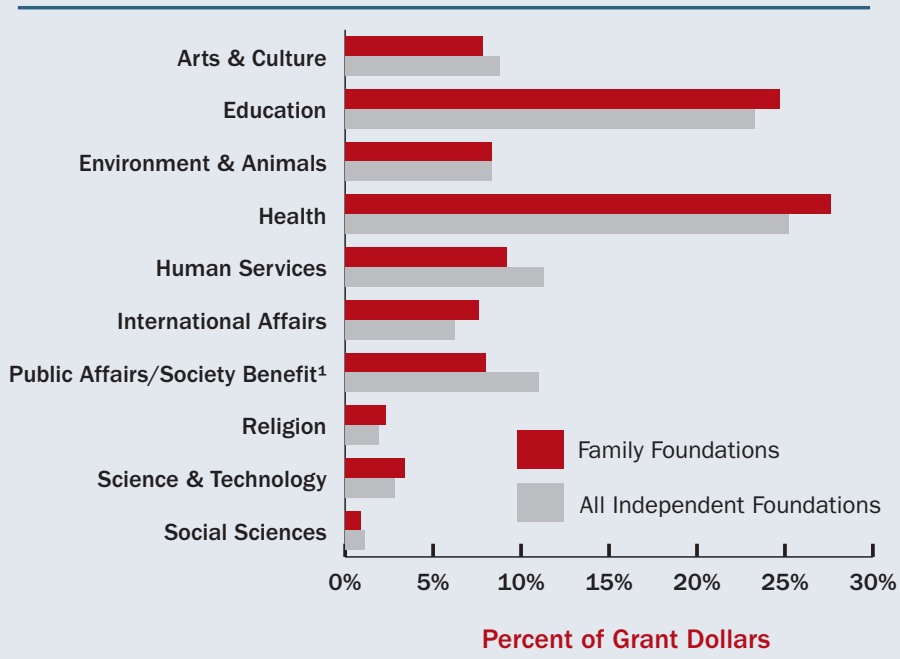

sciences, and gave an equal share for environment and animals. By types of support, family foundations directed similar shares of giving for program, general, and capital support compared to independent foundations overall.

${ }^{1}$ The Foundation Center's 2009 grants sample database included all grants of $\$ 10,000$ or more awarded by 1,384 of the largest U.S. foundations, including 641 family foundations. The overall sample accounted for roughly half of grant dollars awarded by all of the more than 75,000 active U.S. foundations.

\section{Larger family foundations directed the biggest share of their $\mathbf{2 0 0 9}$ giving for programs}

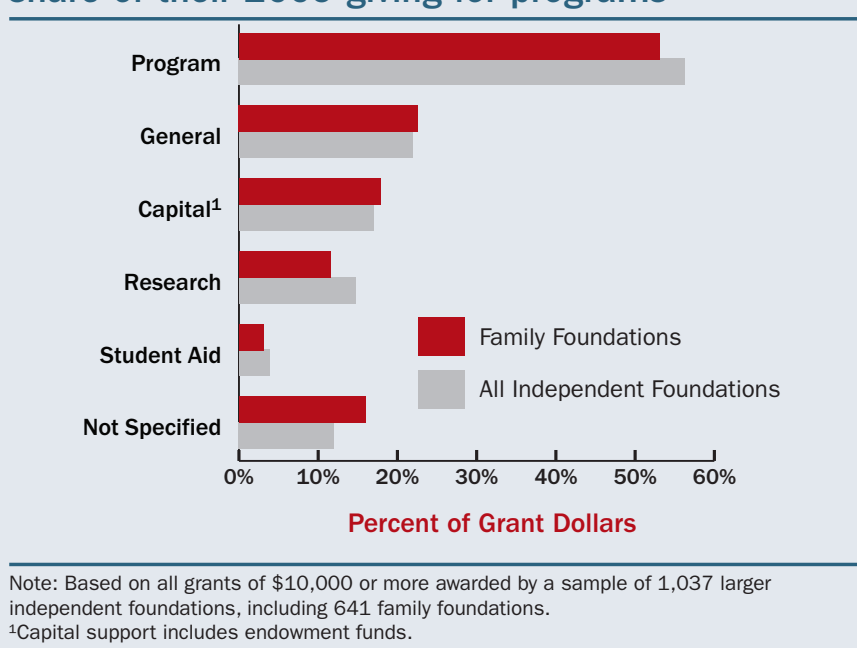

Note: Based on all grants of $\$ 10,000$ or more awarded by a sample of 1,037 larger independent foundations, including 641 family foundations.

1 Includes civil rights and social action, community improvement and development, philanthropy and voluntarism, and public affairs.

\section{Education was the top priority of larger family foundations in three of the four major regions in 2009}

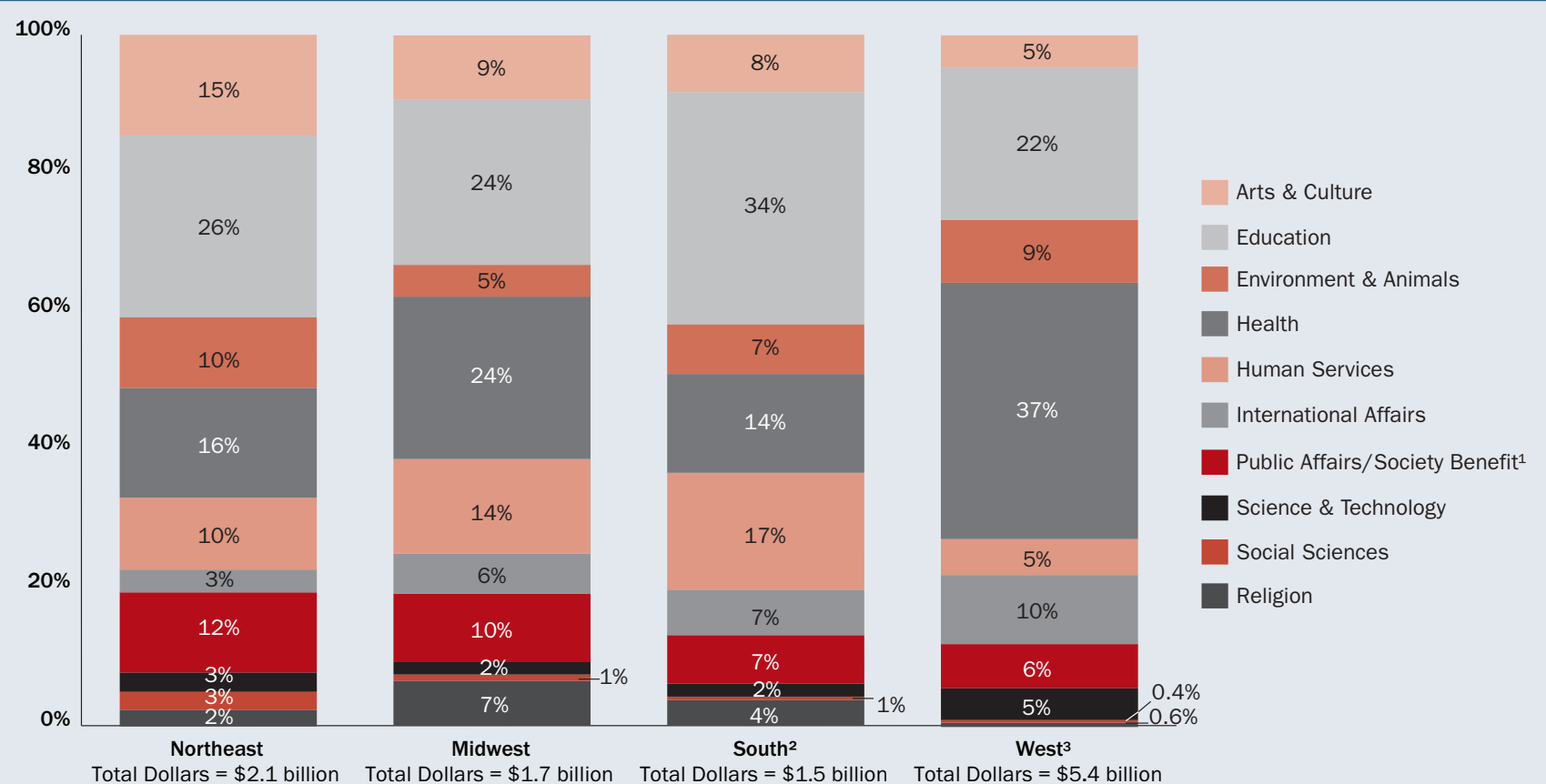

Note: Based on all grants of $\$ 10,000$ or more awarded by a sample of 641 larger family foundations.

1 Includes civil rights and social action, community improvement and development, philanthropy and voluntarism, and public affairs.

${ }^{2}$ Figures for the South exclude the District of Columbia. The DC-based family foundations in the sample awarded grants totaling $\$ 50.7$ million.

${ }^{3}$ Excluding the Bill \& Melinda Gates Foundation-the nation's largest foundation-education ranked first among the funding priorities of Western foundations (26.2 percent), followed by

environment and animals (20.1 percent), health (13 percent), arts and culture (10.1 percent), human services ( 9.9 percent), science and technology ( 8.8 percent), public affairs/society benefit ( 7.3 percent), international affairs ( 2.8 percent), religion ( 1.3 percent), and the social sciences $(0.7$ percent). 
Larger family foundations prioritized giving for the economically disadvantaged in 2009

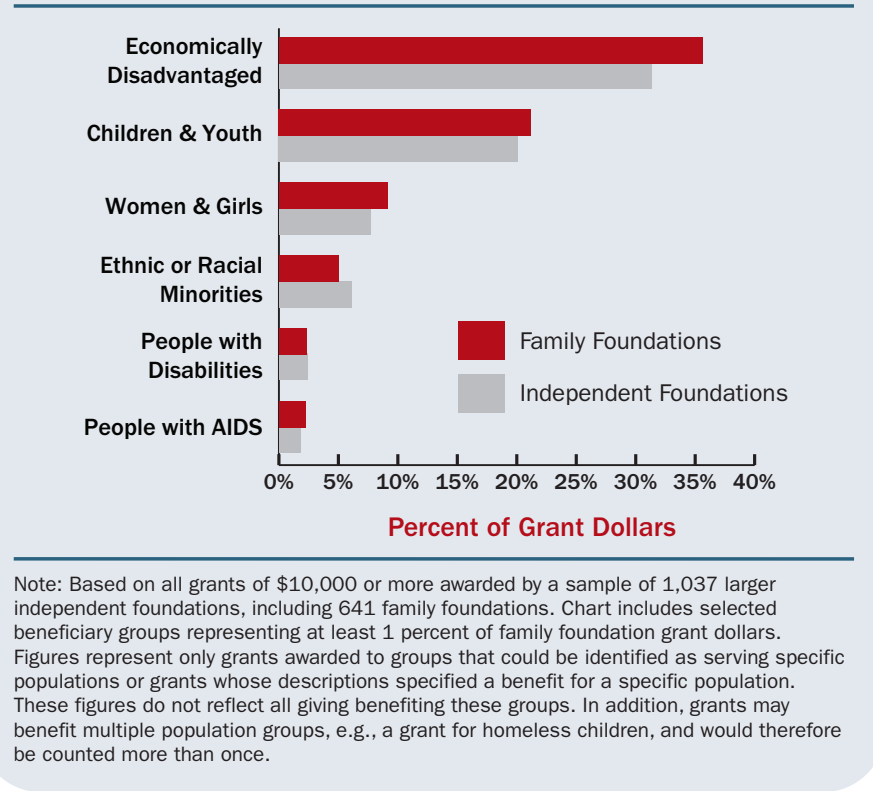

Giving: Nearly half of family foundations reported less than \$50,000 in giving in 2009

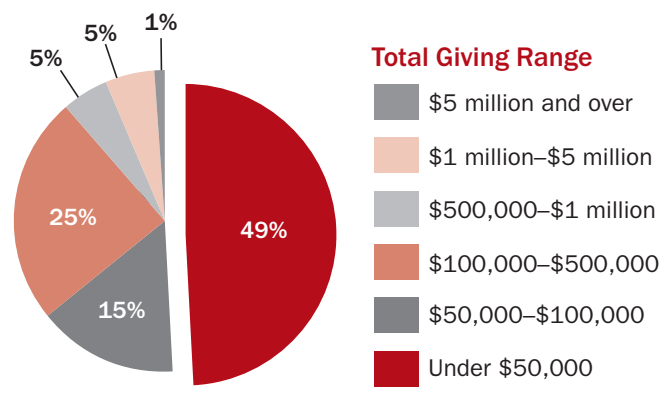

Percent of Foundations

Note: Based on 38,701 grantmaking family foundations. Excludes 2,992 family foundations that did not report giving in the latest fiscal year. Figures for 2009 are preliminary. Due to rounding, figures may not total 100 percent.

Assets: 64 percent of family foundations reported less than $\$ 1$ million in assets in 2009

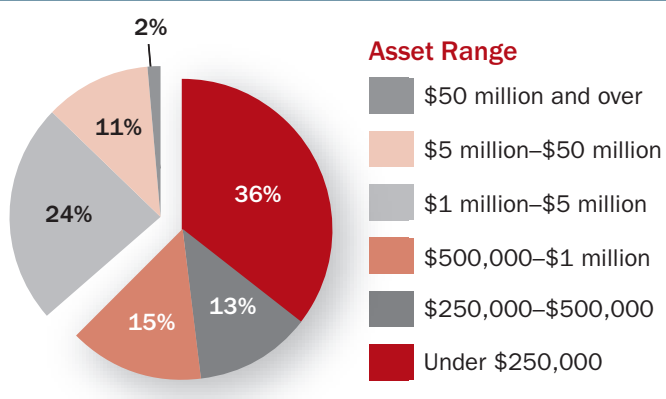

Percent of Foundations

Note: Based on 38,701 grantmaking family foundations. Excludes 2,992 family foundations that did not report giving in the latest fiscal year. Figures for 2009 are preliminary. Due to rounding, did not report giving in the latest fisca
figures may not total 100 percent.
Family foundation board size tends to increase as foundations age

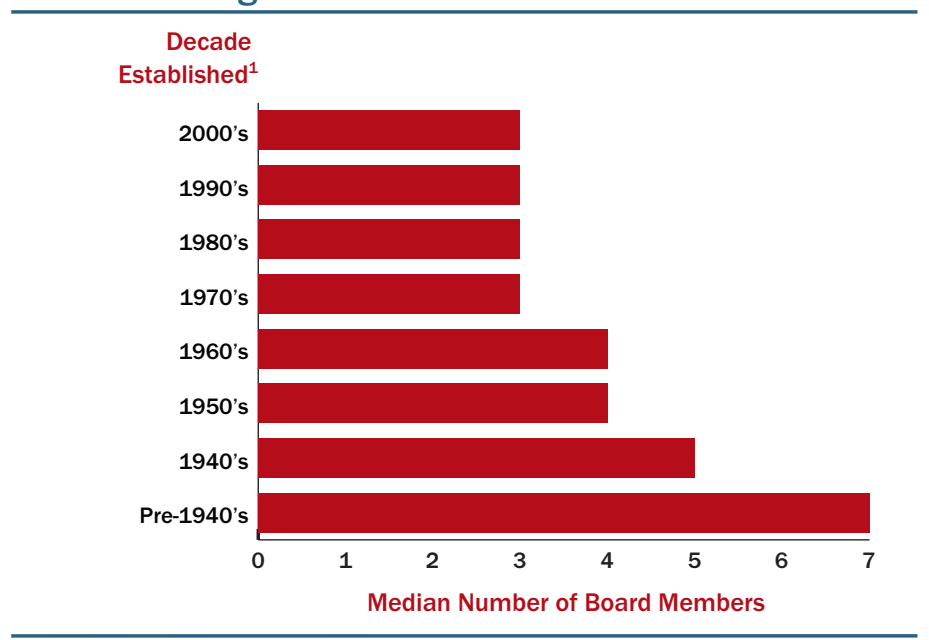

${ }^{1}$ Excludes family foundations lacking establishment information.

One-third of family foundations have been established in the 2000s

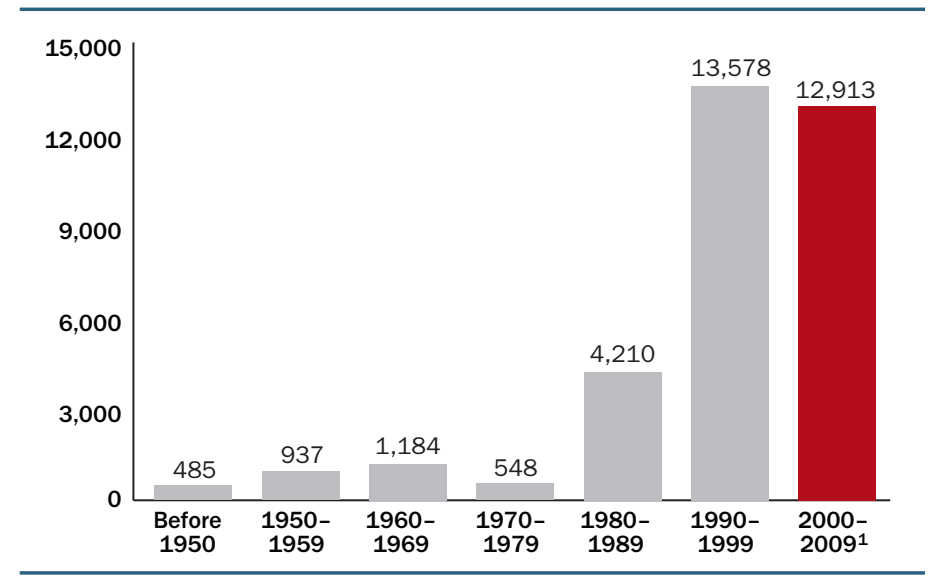

Note: Excludes 4,846 grantmaking family foundations lacking establishment information. 1Data incomplete for period 2000-2009. 


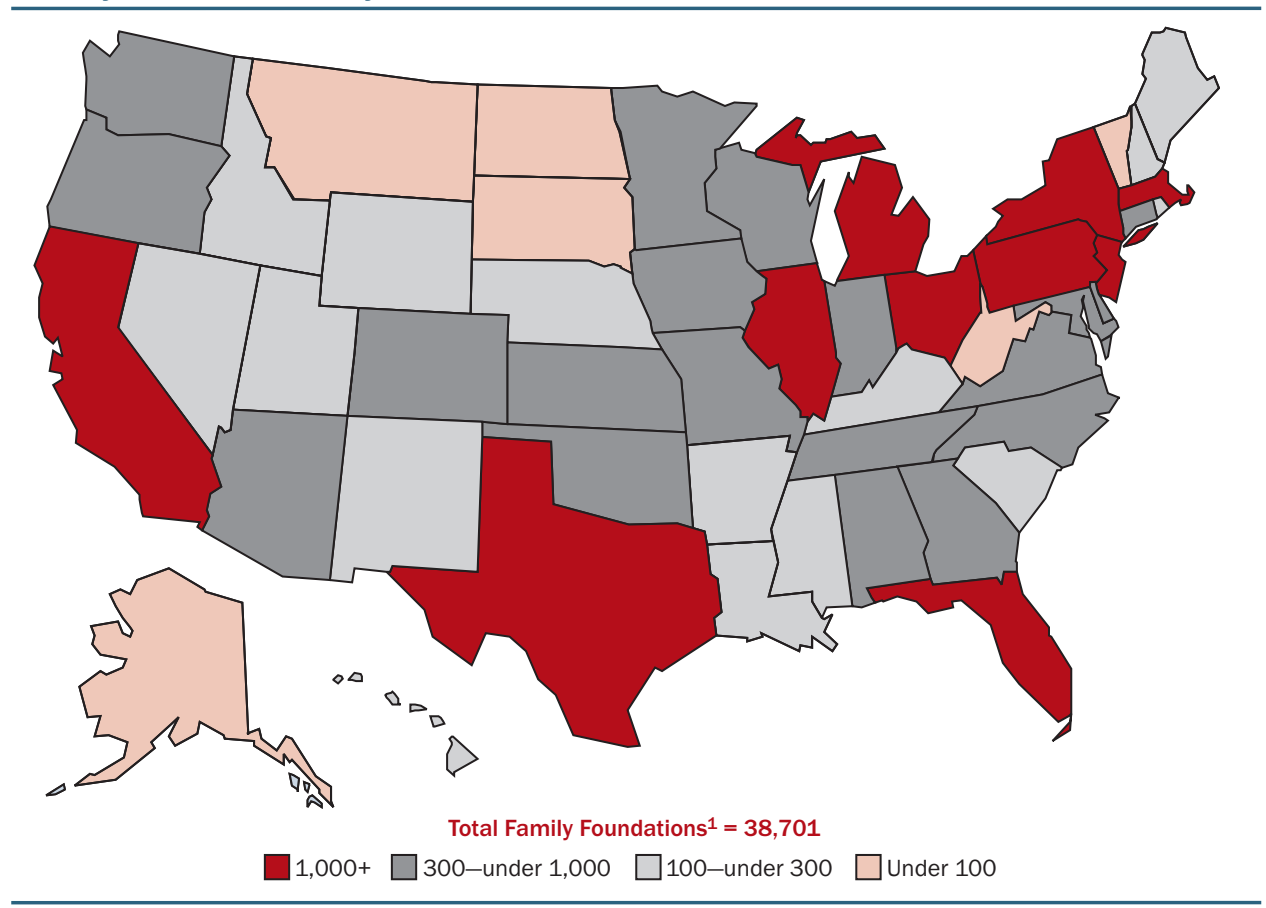

${ }^{1}$ Number of family foundations includes three foundations located in Puerto Rico and six in the Virgin Islands.

Family foundations accounted for three-fifths of overall giving by independent foundations in 2009

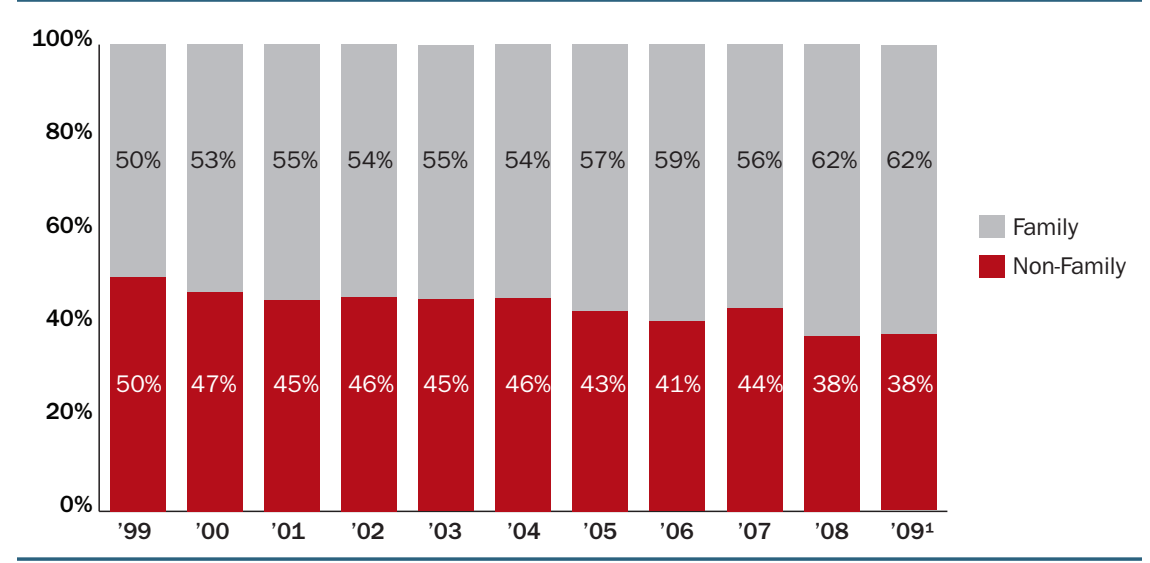

Source for all data: The Foundation Center

Note: Based on 67,379 grantmaking independent foundations, including 38,701 family foundations. Due to rounding, figures may not total 100 percent.

${ }^{1}$ Figures for 2009 are preliminary. 